\title{
Gender Coping Mechanism: A Study in Penang, West Malaysia
}

\author{
Atikah-Hussin, Azlinda Azman \\ Department of Social Work, School of Social Sciences, Universiti Sains Malaysia, Pulau Pinang, Malaysia
}

Email address:

atikah.mhussin@gmail.com (Atikah-Hussin)

\section{To cite this article:}

Atikah-Hussin, Azlinda Azman. Gender Coping Mechanism: A Study in Penang, West Malaysia. Psychology and Behavioral Sciences. Vol. 5, No. 4, 2016, pp. 93-97. doi: 10.11648/j.pbs.20160504.13

Received: March 28, 2016; Accepted: April 20, 2016; Published: July 4, 2016

\begin{abstract}
The death of the loved ones is one of the most stressful events which can happen to a person's life. Previous literature had identified gender differences as one of the factors that influenced humans' coping mechanism post-loss. However, there is limited knowledge in gender differences post-loss in Asia especially. This paper is aimed to understand the gender differences in coping mechanisms after the death of their loved ones among Malaysians. A convenience sample $(\mathrm{N}=$ 90: $\mathrm{n}$ Males $=45 ; \mathrm{n}$ Female $=45$ ) of visitors at one of the Northern region hospital in Malaysia were surveyed. The Ways of Coping Questionnaire (WOC) was administered. The statistical program, SPSS (Statistical Programme for the Social Sciences) Student Version 17.0, was used to process the data collected from the participants. Using Mann-Whitney test and TIndependent test, it was found there is no significant difference between genders in choosing most of the coping mechanisms after the loss of their loved ones except for self-controlling coping mechanism. Findings from this study were contradicted to literature that found gender differences in coping mechanism after the death of loved ones. Hence, this study suggests that gender is not the main factor in determining how people cope with their losses. However, more studies in this area are vital to gain more understanding in gender-related coping mechanisms.
\end{abstract}

Keywords: Gender, Coping Mechanism, Death of Loved Ones

\section{Introduction}

Death is a natural occurrence which every living organism will encounter. However, death is one of the most difficult events to encounter [26]. After the death of a loved one, the bereaved individual might have a possibility to perceive the world in a negative belief [1]. The bereaved individuals may also experience the loss of identity, the loss of relationship with the loved ones, the loss of place and the loss of capacity [10]. As a result, after the death of loved one, bereaved individuals may experience a complex process which to live with memories and to cope with their losses.

One of the most discussed issues were the ability for bereaved individuals to cope with their losses with the influenced of their gender [2, 20]; [24]. Literature had identified that the uniqueness of each gender in coping with their losses may varies accordingly to their cognitive skills and interaction with other people around them. However, there are limited studies related to gender coping mechanisms especially related to grief in Malaysia. This study is aimed to understand the gender-related coping mechanisms among Malaysian. Even though there were studies related gender differences coping mechanisms however, the understanding on gender coping mechanism after the death of loved ones in Malaysia is still limited.

\subsection{Death of Loved Ones and Gender Related Coping Mechanisms}

Even though death of a loved one is difficult to handle, the bereaved individuals still need to confront with the loss. This process is called coping process [11]. Estimated, 80\% - $90 \%$ of bereaved individuals experience normal grief [36]. Normal grief is described as the ability for bereaved individuals to bounce back from their grief feelings after few months' time after the loss and normally move on with their daily activities [36]. The ability for them to cope with their loss is depending on bereaved individuals' coping mechanisms. 
Literature had argued that gender is one of the significant factors that influenced bereaved individuals' coping mechanisms. A study on spousal death found that widowers experienced greater depression and health consequences compared to widows [26]. In extending studies on gender and coping mechanism found that men tend to experience, unrecognized problems due to their socialization interfere with active grief processes [4]. Studies on parental grief found that bereaved fathers reported being too depressed, covering their feelings and avoiding other people than the bereaved mothers [22, 33, 35]. Martin and Doka (2000) identified that men's grief as instrumental grief. Instrumental grief is described as using cognitive and problem-solving ways in dealing with their losses. In addition, men's grief is also called masculine grief $[2,20$, 24]. Men's grief is influenced by males' masculinity characteristics which influenced men to be decisive, strong, successful, and inexpressive after the death of a loved one $[23,31]$.

On the other hand, females display their emotions more but commonly grief longer than males [16]. They are also reported to experience more intense grieving style with sorrow guilt and depression [4]. Females' grief is described as loss-oriented [26]. Loss-oriented grief is defined as a process which bereaved individuals focus on the loss and solve the problem with their perspectives. Females reported to use most coping mechanisms to deal with their losses [27]; [32]. In a research on parental grief, it was found that the bereaved mothers were more likely to find support from others by having someone to talk about their experiences [17]. It can be said that females seek for support from other people around them by sharing their grief feelings. The ability for females to communicate provides a medium for them to gain support from other people. With talking and sharing about their losses with other people, females are able to understand their situation better.

After all, these arguments lead to the understanding on gender-related coping mechanisms among both genders. Men prefer to exclude themselves from the society and choose to grief privately while women tend to seek for support from other people around them. However, it is important to note that women's ability to seek support is contributed to their capability to express their feelings as compared to men who prefer to reserve their feelings. This study is vital in order to understand the coping mechanisms used by both genders. The understanding on this issue will help to understand that bereaved individuals may cope differently or similarly after the death of their loved ones. The understanding is vital especially among professional helpers who work with bereaved individuals and the understanding may help them to identify appropriate intervention which can be applied for both genders.

\subsection{Objective}

This study is aimed to:

1. To identify gender-related coping mechanisms after the death of their loved ones.
2. To investigate gender differences in coping mechanism after the death of their loved ones.

\section{Method}

\subsection{Sampling Method}

This study applied convenience sampling method to recruit respondents. The respondents were among visitors of one of the Northern region part hospital in Malaysia. Initially, they were asked if they had experienced the death of loved ones in their life. Those who had were invited to participate in this research. The loved ones are identified as only family members. This method was chosen as there is no specific organization or institution which gathers bereaved individuals in Malaysia.

\subsection{Participants}

Participants were recruited at one of the Northern region part hospital in Malaysia. Participants were 90 Malaysians (45 males and 45 females). The age range of male participants are between 18 to 60 years old $(M=42)$. The age range of female participants are 20 to 59 years old $(\mathrm{M}=$ 43.05). The participants came from various races (Malays= 63, Chinese $=19$, Indians $=8$ ). All of the respondents reported experiencing the death of their grandmothers $(n=27)$, grandfathers $(\mathrm{n}=26)$, other relatives, such as nephews, cousins or in laws $(n=7)$, fathers $(n=5)$, mothers $(n=5)$, child $(\mathrm{n}=1)$ and more than one relationships $(\mathrm{n}=19)$.

\subsection{Instruments}

The primary research instrument for this study is the Way of Coping Questionnaire (WCQ) originally designed by Susan Folkman (1985) from University of California, San Francisco. The questionnaire consists of eight components of coping mechanisms as stated in the questionnaire. They are confronting coping, distancing, self-controlling, seeking social support, accepting responsibility, escape avoidance, planful problem solving and positive reappraisal.

The confronting coping is described as aggressive efforts to alter the situation and suggests some degree of hostility and risk-taking. The Distancing coping is a cognitive effort to one self and to minimize the significance of the situation. The self-Controlling describes as efforts to regulate one's feelings and actions. The seeking social coping support is described as efforts to seek informational support, tangible support, and emotional support. The accepting responsibility is described as acknowledges one's role in the problem with a concomitant theme of trying to put things right. Escape-Avoidance is explained as wishful thinking and behavioral efforts to escape or avoid the problem. Items on this scale contrast with those on the Distancing scale, which suggest detachment. Planful problem solving is explained as deliberate problem-focused efforts to alter the situation, coupled with an analytic approach to solving the problem. While positive reappraisal is described as efforts to create positive meaning by focusing on personal growth. 
It also has a religious dimension.

\subsection{Procedures}

The respondents were asked to sign the informed consents before they started to answer the questionnaires. The questionnaires were written in a bilingual version which is in English and Bahasa Malaysia. It took approximately 20 minutes for respondents to complete the questionnaire.

During the questionnaire answering session, the respondents were free to ask any question that they did not understand while answering the WCQ. The researcher had explained that this is a volunteer participation. There was no reward for answering this questionnaire. The participants were invited to answer the questionnaires individually. This study involved no or minimal risk to the respondents' wellbeing. The researcher also explained there was no right or wrong answers. They should respond to the questions according to their point of view. After the respondents had finished answering the questionnaire, the researcher collected the questionnaire and computed the data using SPSS.

\subsection{Data Analysis}

Data analysis focused on identifying the coping mechanisms employed after the death of the loved one with comparisons made based on gender. The goal was to identify and reveal the coping mechanisms used a different gender. SPSS was used to analyze the descriptive statistics and Mann-Whitney Test. The Mann-Whitney Test was used to identify significant differences between two means. The significant differences in the means represented the differences in gender coping mechanisms.

\section{Mann Whitney Test Result}

As the data regarding the relationships between gender and positive reappraisal, planning problem solving, escape avoidance, accepting responsibilities, self-controlling, distancing and confronting coping mechanisms showed not normal distributions, Mann-Whitney $U$ test was employed in analyzing the significant differences between genders in their chosen coping mechanisms. The significant $\mathrm{p}$ values were compared to understand the relationships. According to the table, the confronting coping mechanism $(\mathrm{p}=0.945)$, distancing coping mechanism $(\mathrm{p}=0.251)$, accepting responsibilities coping mechanism $(\mathrm{p}=0.87)$, escape coping mechanism $(\mathrm{p}=0.573)$, planning problem solving coping mechanism $(\mathrm{p}=0.760)$, seeking for social support $(\mathrm{p}=0.946)$ and positive reappraisal coping mechanism $(\mathrm{p}=0.102)$ had shown no significant values, $\mathrm{p}>0.05$.

Self-controlling coping mechanism $(p=0.03)$ had shown significant value which denotes the significant differences between gender to use self-controlling coping mechanism after the death of their loved ones.
Table 1. Mann-Whitney Test, Loss Coping Mechanisms between males and Females.

\begin{tabular}{llllll}
\hline Coping Scale & Gender & N & $\begin{array}{l}\text { Mean } \\
\text { Rank }\end{array}$ & $\begin{array}{l}\text { Significant, } \\
\text { p value }\end{array}$ & $\begin{array}{l}\text { Mann } \\
\text { Whitney-U }\end{array}$ \\
\hline Confronting & Male & 45 & 45.31 & & \\
coping & $\begin{array}{l}\text { Female } \\
\text { Total }\end{array}$ & 45 & 45.69 & 0.95 & 1004 \\
& Male & 45 & 48.63 & & \\
Distancing & Female & 45 & 42.37 & 0.25 & 872 \\
coping & Total & 90 & & & \\
& Male & 45 & 42.92 & & \\
Seeking Social & Female & 45 & 48.08 & 0.51 & 913 \\
Support & Total & 90 & & & \\
Self- & Male & 45 & 53.62 & & \\
controlling & Female & 45 & 37.38 & $0.03 *$ & 647 \\
coping & Total & 90 & & & \\
Accepting & Male & 45 & 50.16 & & \\
responsibility & Female & 45 & 40.84 & 0.87 & 803 \\
& Total & 90 & & & \\
Escape- & Male & 45 & 43.96 & & \\
avoidance & Female & 45 & 47.04 & 0.57 & 943 \\
Planning & Total & 90 & & & \\
problem & Male & 45 & 44.67 & & \\
solving & Female & 45 & 46.33 & 0.76 & 975 \\
Positive & Total & 90 & & & \\
reappraisal & Male & 45 & 49.98 & & \\
\hline & Female & 45 & 41.02 & 0.10 & 811 \\
\hline
\end{tabular}

$* \alpha=0.01$

\section{Discussion}

These findings suggested that there is no statistically significant relationship between gender and confronting, distancing, social seeking, escape avoidance, accepting, planful problem solving and positive reappraisal coping mechanisms. Both genders might use these coping mechanisms at roughly the same rate in dealing with the loss of loved ones. This is consistent with the previous literature which proved no significant difference in gender coping mechanism (Hoar, Crocker, Holt \& Tamminen, 2010). The findings for this study showed that gender did not influence individuals' coping mechanism. There may be other factors which influence the individuals' coping mechanism such as religion and culture. However, more studies on understanding factors which influence bereaved individuals after the death of their loved ones are vital in order to confirm that there are other factors that influence grief.

Nevertheless, the self-control coping mechanism significant differences showed significance different in gender related coping mechanism. This study gains the understanding that men in Malaysia pose greater ability to control their grief feelings. This may have the relationship with gender-linked personality (Helgeson \& Lepore, 2004; Hoyt \& Stanton, 2011) which expect the males to be independent, self-reliant, in control, powerful, strong, and stoic (Courtenay, 2000; Spector-Mersel, 2006; Hoonaard, 2009). The ability for them to control their feelings is contributed by the masculinity characteristics that they have and social expectation which expect them to be strong even in stressful situation. These include the responsibility to 
support their family members, partners or spouses in dealing with the loss. With the responsibility to act as a protector, men need to show that they are strong even in stressful situation so that people are confident to rely on them. In addition, this answered the question which men are able to reserve their grief feelings after the death of their loved ones. As discussed in the previous literature, this study supported that men tend to control their feelings and prefer of not showing their feelings to others.

Nevertheless, this study did not reveal any issues related to the consequences of using certain forms of coping mechanisms. More studies related to gender-related coping mechanisms and the consequences after using the coping mechanisms is vital especially to understand gender related issues, grief and coping mechanism. Hopefully, this research will help spur more research regarding bereavement and coping. However, as a starter, we can consider the relationship between gender and coping as depicted in this study and consider the desirability for a specific service to be implemented in all Malaysian hospitals for addressing the needs of the families who have lost loved ones, particularly when that loss is sudden or tragic. Such a service could aid families in handling their grief, avoid unresolved grief, and be a channel where families can address their sadness after the loss.

\section{References}

[1] Boelen, P. A., \& Van Den Bout, J. (2002-2003). Gender differences in traumatic grief symptom severity after the loss of a spouse. Omega, 46, 183-198.

[2] Corr, C. A., Nabe, C. M., \& Corr, D. M. (2000). Death and dying, life and living (3rd ed.). Belmont, CA: Wadsworth/Thomson Learning.

[3] Courtenay, W. H. (2000). Constructions of masculinity and their influence on men's well-being: A theory of gender and health. Social Science \& Medicine, 50, 1385-1401. doi: 10.1016/S0277-9536(99)00390-1.

[4] Doka, K. J., \& Martin, T. (2001). Take it like a man: Masculine response to loss. In D. A. Lund (Ed.), Men coping with grief (pp. 37-47). Amityville, NY: Baywood.

[5] Ellis, RT., \& Granger, M. (2002). African American adults' perceptions of the effects of parental loss during adolescence. Child and Adolescent Social Work Journal, 19 (4), 271- 284.

[6] Folkman, S., Lazarus, R. S., Dunkel-Schetter, C., DeLongis, A., \& Gruen, R. (1986). The dynamics of a stressful encounter: Cognitive appraisal, coping and encounter outcomes. Journal of Personality and Social Psychology, 50, 992-1003.

[7] Folkman, S., Chesney, M., Collette, L., Boccellari, A., \& Cooke, M. (1996). Postbereavement depressive mood and its prebereavement predictors in $\mathrm{HIV}+$ and HIV-gay men. Journal of Personality and Social Psychology, 70, 336-348.

[8] Folkman, S. (1997a). Introduction to the special section: Use of bereavement narratives to predict wellbeing in gay men whose partner died of AIDS-Four theoretical perspectives. Journal of Personality and Social Psychology, 72, 851-854.
[9] Haine, RA, Ayers, T. S., Sandler, IN., \& Wolchik, S. A (2008). Evidence-based practices for parentally bereaved children and their families. Professional Psychology: Research and Practice, 39 (2), 113-121.

[10] Halifax, J. (2008). Being with dying: Cultivating compassion and fearlessness in the presence of death. Boston: Shambhala.

[11] Hall, M., \& Irwin, M. (2001). Physiological indices of functioning in bereavement. In M. S. Stroebe, R. O. Hansson, W. Stroebe, \& H. Schut (Eds.), Handbook of bereavement research: Consequences, coping, and care (pp. 473-492). Washington, DC: American Psychological Association.

[12] Hampel, P. \& Petermann, F. (2005). Age and gender effects on coping in children and adolescents. Journal of Youth and Adolescence, 34 (2), 73-83.

[13] Helgeson, V. S., \& Lepore, S. J. (2004). Quality of life following prostate cancer: The role of agency and unmitigated agency. Journal of Applied Social Psychology, 34, 2559 2585. doi: $10.1111 /$ j.1559-1816.2004.tb01992. x.

[14] Hoyt, M. A., \& Stanton, A. L. (2011). Unmitigated agency, social support, and psychological adjustment in men with cancer. Journal of Personality, 79, $259-276$. doi: 10.1111/j.1467-6494.2010.00675.x.

[15] Hoar, S. D., Crocker, P. R. E., Holt, N. L. \& Tamminen, K. (2010). Gender Differences in Adolescent Athletes' Coping with Interpersonal Stressors in Sport: More Similarities than Differences? Journal of Applied Sport Psychology, 22 (2), 134-149.

[16] Hooyman, N. R. \& Kramer, B. J. (2006). Living through loss: Interventions across the life span. New York: Columbia University Press.

[17] Kavanaugh, K., Trier, D., \& Korzec, M. (2004). Social support following perinatal loss. Journal of Family Nursing, 10, 7092.

[18] Lips, H. M. (1997). Sex and Gender: An Introduction (3rd ed.). Mountain View, CA: Mayfield.

[19] Martin, T. L., \& Doka, K. J. (2000). Men don't cry... women do: Transcending gender stereotypes of grief. Philadelphia: Brunner Mazel.

[20] Nolen-Hoeksema, S., \& Larson, J. (1999). Coping with loss. Mahwah, NJ: Erlbaum. Nolen- Hoeksema, S., McBride, A., \& Larson, J. (1997). Rumination and psychological distress among bereaved partners. Journal of Personality and Social Psychology, 72, 855-862.

[21] Ptacek, J. T., Smith, R. E. \& Dodge, K. L. (1994). Gender differences in coping with stress: when stressors and appraisal do not differ. Personality and Social Psychology Bulletin 20, 421-430.

[22] Samuelsson, M., Rådestad, I., \& Segesten, K. (2001). A waste of life: Fathers' experience of losing a child before birth. Birth, 28, 124-130.

[23] Stillion, J. M., \& McDowell, E. E. (2001-2002). The early demise of the "stronger" sex: Genderrelated causes of sex differences in longevity. Omega, 44, 301-318.

[24] Stinson, K., Lasker, J., Lohmann, J., \& Toedter, L. (1992). Parental grief following pregnancy loss: A comparison of mothers and fathers. Family Relations, 41, 218-223. 
[25] Spector-Mersel, G. (2006). Never-ending stories: Western hegemonic masculinity scripts. Journal of Gender Studies, 15, 67-82. doi: 10.1080/ 09589230500486934.

[26] Stroebe, M. S., \& Schut, H. (2001). Models of coping with bereavement: A review. In M. S. Stroebe, R. O. Hansson, W. Stroebe, \& H. Schut (Eds.), Handbook of bereavement research: Consequences, coping, and care (pp. 375-403). Washington, DC: American Psychological Association.

[27] Tamres, L. K., Janicki, D. \& Helgeson, V. S. (2002). Sex differences in coping behavior: A metaanalytic review and an examination of relative coping. Personality and Social Psychology Review, 6 (1), 2-30.

[28] van den Hoonaard, D. K. (2009). I was the man: The challenges of masculinity in older men. In Z. D. Buchholz \& S. K. Boyce (Eds.), Masculinity: Gender roles, characteristics and coping (pp. 69-84). New York, NY: Nova Science.

[29] Vance, J., Boyle, F., Najman, J., \& Thearle, J. (1995). Gender differences in parental psychological distress following perinatal death or sudden infant death syndrome. British Journal of Psychiatry, 167, 806-811.

[30] Washburn-Ormachea, J. M., Hillman, S. B. \& Sawilowsky, S.
A. (2004). Gender and gender-role orientation differences on adolescents' coping with peer stressors. Journal of Youth and Adolescence, 33 (1), 31-40.

[31] White, H., \& Stillion, J. M. (1988). Sex differences in attitudes toward suicide: Do males stigmatize males? Psychology of Women Quarterly, 12, 357-366.

[32] Wilson, G. S., Pritchard, M. E. \& Revalee, B. (2005). Individual differences in adolescent health symptoms: the effects on gender and coping. Journal of Adolescence, 28, 369-379.

[33] Wood, J., \& Milo, E. (2001). Father's grief when a disabled child dies. Death Studies, 25, 635-661.

[34] Worden, IW. (1996). Children and grief' When a parent dies. New York: The Guilford Press.

[35] Worth, N. (1997). Becoming a father to a stillborn child. Clinical Nursing Research, 6, 71-89.

[36] Zhang, B., El-Jawahri, A., \& Prigerson, H. G. (2006). Update on bereavement research: Evidence-based guidelines for the diagnosis and treatment of complicated bereavement. Journal of Palliative Medicine, 9, 1188-1203. 